\title{
Fundamentación y estructura de los derechos sociales
}

\author{
Sebastián Salazar Pizarro*
}

RESUMEN

Se entrega una aproximación dogmática y doctrinal de los derechos sociales distinta a la señalada por parte importante de la doctrina constitucionalista catalogada como tradicional o clásica, tanto en nuestro país como en el ámbito comparado, con la finalidad de establecer un intento de un nuevo marco teórico que permita un cabal entendimiento sobre estos derechos fundamentales.

Derechos fundamentales - derechos sociales - derechos subjetivos

The rationale and structure of social rights

\begin{abstract}
The article introduces a dogmatic and doctrinal approach to social rights in contrast to that cited by major constitutional doctrine and labelled as classic and traditional both in domestic and comparative jurisdictions. This is done with the aim of establishing a new theoretical framework to enable a full understanding of these fundamental rights.
\end{abstract}

Fundamental rights - social rights - subjective rights

\section{INTRODUCCIÓN}

$\mathrm{E}$ 1 debate sobre los derechos sociales, sea en el discurso político como también en el ámbito jurídico, no es pacífico. Diversas posturas establecen o cuestionan el carácter de fundamentales de los derechos sociales.

En este último sentido, se ha destacado por posiciones doctrinales constitucionalistas mayoritarias que los derechos comentados corresponden a disposiciones programáticas, mandatos de optimización, derechos debilitados u otros adjetivos que implican

* Abogado. Licenciado en Ciencias Jurídicas y Sociales. Ayudante de Derecho Constitucional Universidad Alberto Hurtado, Santiago de Chile. Correo electrónico: sebasalazarp@gmail.com

Artículo recibido el 15 de marzo de 2013 y aceptado para su publicación por el Comité Editorial el 29 de mayo de 2013. 
cuestionamientos a la fundamentalidad de los derechos sociales, principalmente cuando son comparados con las libertades y derechos civiles y políticos ${ }^{1}$. El principal argumento de las teorías tradicionales radica en el concepto de derecho subjetivo que utilizan para determinar la noción de derechos fundamentales ${ }^{2}$.

Tales consideraciones corresponden a la particular lógica que poseen ciertos sectores sobre la Constitución, los cuales sostienen que la tarea primordial de la norma fundamental es limitar al poder político y consagrar únicamente los derechos provenientes del constitucionalismo liberal. Cualquier otra noción que no se encuentre en armonía con lo sostenido precedentemente es considerada como infraconstitucional por parte de esta concepción constitucional ${ }^{3}$.

Tal es la situación que han experimentado los derechos sociales. La idea de esta investigación es realizar un análisis teórico de los citados derechos que sea distinta a la citada explicación, al abordar aspectos trascendentales de estos, como la igualdad material o sustancial que sirve de su fundamento; su estructura, y en específico el concepto amplio de derechos subjetivos, dejando a un lado la idea de exigibilidad ante órganos jurisdiccionales como principal elemento de este; la titularidad que corresponde al individuo; el Estado y los particulares como sujetos pasivos y el carácter heterogéneo de las diversas obligaciones contenidas en los derechos que estudiaremos, lo que nos permitirá una nueva conceptualización de los derechos sociales ${ }^{4}$, estableciéndose como un intento que permita un cabal y verdadero entendimiento de estos derechos fundamentales.

${ }^{1}$ Los principales argumentos que se esgrimen para sostener dichas categorizaciones son metajurídicos, destacándose principalmente razones económicas o de capacidad de implementación de políticas públicas; el no ser derechos absolutos por recoger principios, programas o aspiraciones político-sociales; dependientes de la opinión pública del momento; y por no ser inherentes a la noción de Constitución. Martínez Estay, J.I., "Los Derechos Sociales de Prestación en la Jurisprudencia Chilena", en Revista Estudios Constitucionales, Vol. $8 \mathrm{~N}^{\circ}$ 2, 2010, pp. 125-166.

${ }^{2}$ Para una breve ejemplificación de lo aseverado, se recomienda ver a Martínez Estay, J.I., "Los Derechos Sociales: Una reflexión a propósito de la sentencia Rol 976 del Tribunal Constitucional”, en Nomos, Vol. 2, 2008, pp. 275-290.

${ }^{3}$ En este mismo punto, el profesor Tomás Jordán sostiene que esta idea es reflejo de una matriz mental inamovible, que se sitúa en una posición autodefensiva, donde todo aquello que no responda a dicha matriz queda automáticamente fuera de la órbita constitucional. Jordán Díaz, T., "Algunos comentarios a la Sentencia del Tribunal Constitucional N 976/2008”, en Nomos, Vol. 2, 2008, pp. 263. Es interesante destacar la reflexión que formula Francisco Ansuátegui, quien citando a Norberto Bobbio y a Carlos Santiago Nino sostiene que nos encontramos con cuestionamientos más bien ideológicos que teóricos por parte de los principales detractores de que los derechos sociales sean considerados como derechos fundamentales (liberalismo conservador según Nino), lo que implica una confusión en tres órdenes de idea, a saber: (i) el carácter natural y espontáneo del mercado; (ii) que la autonomía personal está constituida únicamente por condiciones negativas; y (iii) las confusiones que se originan entre las condiciones normativas y materiales de la libertad. Ansuátegui Roig, F., "Argumentos para una teoría de los derechos sociales”, en Revista Derecho del Estado, Vol. 24, 2010, p.49.

${ }^{4}$ Con la finalidad de conocer el estado de la discusión acerca de diversas temáticas relacionadas con los derechos sociales en la literatura constitucional anglosajona, se recomienda ver los siguientes artículos: Figueroa García-Huidobro, R., "Justiciabilidad del Rol de las Cortes Haciendo Justiciables los Derechos Económicos, Sociales y Culturales, en particular, el Derecho a la Protección de la Salud”, en Revista Chilena de Derecho, Vol. 36 N 2, 2009, pp. 313-342, y Figueroa García-Huidobro, R., "Justiciabilidad de los 


\section{LA FUNDAMENTACIÓN DE LOS DERECHOS SOCIALES}

La discusión sobre la fundamentación de los derechos fundamentales ${ }^{5}$ es una problemática actualmente atingente, ya que todo derecho necesita de una justificación iusfilosófica y jurídica que le permita su desarrollo y su posterior aplicabilidad dentro de un Estado Democrático y Social de Derecho ${ }^{6}$.

Los derechos sociales también poseen una fundamentación iusfilosófica propia, como ocurre con los derechos de libertad que poseen una justificación particular, que determinará su existencia y su contenido ${ }^{7}$. No obstante lo anterior, no existe un consenso por parte de la doctrina constitucional sobre el fundamento de los derechos sociales. A continuación se procederá a describir someramente las distintas nociones o tesis que fundamentan a los derechos sociales, para luego tomar una postura al respecto.

Derechos Económicos, Sociales y Culturales. Discusión Teórica”, en Revista Chilena de Derecho, Vol. 36 Nº 3 , 2009, pp. 587-620.

${ }^{5}$ Para efectos de esta monografía, entenderemos como concepto de derechos fundamentales el entregado por Gregorio Peces-Barba, quien sostiene que corresponde a una categoría que comprende tanto presupuestos éticos como componentes jurídicos, significando la relevancia moral de una idea que compromete la dignidad humana y sus objetivos de autonomía moral, y también la relevancia jurídica que convierte a los derechos en norma básica material del ordenamiento (jurídico), y es instrumento necesario para que el individuo desarrolle en la sociedad todas sus potencialidades. Peces-Barba, G., Curso de derechos fundamentales: teoría general, Universidad Carlos III de Madrid, Boletín Oficial del Estado, Madrid, 1999, p. 37. A su vez, Robert Alexy indica que los derechos fundamentales son posiciones tan importantes que su otorgamiento o no otorgamiento no puede quedar en manos de una simple mayoría parlamentaria. Alexy, R., Teoría de los derechos fundamentales, Centro de Estudios Políticos y Constitucionales, Madrid, 1997, p. 406. Luigi Ferrajoli define a los derechos fundamentales como todos aquellos derechos subjetivos que corresponden universalmente a todos los seres humanos en cuanto dotados del estatus de personas, de ciudadanos o de personas con capacidad de obrar. Ferrajoli, L., "Derechos Fundamentales", en Los Fundamentos de los Derechos Fundamentales, Trotta, Madrid, 2001, p. 19.

${ }^{6}$ En esta denominación seguimos el modelo inspirado por las Constituciones alemana y española. Para la evolución histórica del Estado Social y Democrático de Derecho se recomienda ver a Carbonell, M., "Eficacia de la Constitución y Derechos Sociales: esbozo de algunos problemas", en Revista Estudios Constitucionales, Vol. 6, No 2, 2008, pp. 43-71. Es importante sostener que los derechos fundamentales definen el modelo de Estado, y que determinado modelo de Estado se realiza mediante sus derechos fundamentales, ya que el constituyente tendrá una idea de lo que entiende por político y por jurídico, expresándolas por medio de principios y reglas que constituirán un modelo constitucional, lo que resulta cardinal para entender su respectiva conformación. Los elementos distintivos entre uno y otro modelo será el binomio autonomía del individuo vs intervención estatal. Así, un modelo liberal consagrará más libertades y derechos de libertad o defensa, entregándoles a las personas las titularidades de dichas libertades; de manera inversa, el Estado fijará derechos bajo premisas igualitaristas, definiendo el grado de intervención de estos. Jordán Díaz, T., "El principio de contribución constitucional y la abrogación del principio de subsidiariedad en materia de derechos fundamentales sociales", en Ferrada, J. C (Coord.), Estudios de Derecho Público. El principio de separación de poderes, Actas de las XL Jornadas de Derecho Público 2010, Abeledo Perrot - Thompson Reuters, Santiago, 2011, p. 559.

${ }^{7}$ Jordán Díaz, T., La Protección de los Derechos Sociales: Modelos Jurisprudenciales Comparados de tutela en España y Chile, Colección de Investigaciones Jurídicas $\mathrm{N}^{\circ} 10$, Facultad de Derecho Universidad Alberto Hurtado, 2006, p. 42. 


\subsection{Las diversas fundamentaciones de los derechos sociales}

\subsubsection{La libertad fáctica}

La utilización de la libertad como fundamento de los derechos sociales se encuentra inspirado en autores tales como Robert Alexy y E.W. Böckenförde, principalmente. Alexy señala que existen dos tesis para fundamentar los derechos sociales bajo el argumento de libertad, indicándose que la libertad jurídica para obrar u omitirse sin la libertad real o fáctica, no pudiendo realmente elegir, carece de todo valor. Considerando las características propias de la sociedad moderna industrial, la libertad fáctica de muchísimos titulares de los derechos fundamentales no encuentra sustrato material en un ambiente dominado por dichos titulares, sino que dependen básicamente de actividades estatales ${ }^{8}$.

A su vez, Böckenförde sostiene que los derechos fundamentales sociales encuentran su justificación no como un contraprincipio frente a los derechos de libertad, sino a partir del propio principio del aseguramiento de la libertad. Sostiene también que si la libertad jurídica debe poder transformarse en libertad real, sus titulares precisan de una participación básica en los bienes sociales materiales, incluso esta participación en los bienes materiales es una parte de la libertad, debido a que es un presupuesto necesario para su realización ${ }^{9}$. Agrega además que la libertad se asegura por medio de prestaciones por parte del Estado, lo que permite afirmar que no existe una contradicción entre libertad liberal-burgués y derechos sociales, sino, más bien, que estos son una consecuencia lógico-material de una situación social modificada ${ }^{10}$.

Del análisis de ambas tesis podemos establecer que el argumento que justifica la existencia de los derechos sociales basado en la libertad fáctica limita estos derechos, al ser considerados simplemente como una "condición necesaria" para el desarrollo del individuo mediante la libertad, sosteniéndose que la libertad se logra por la igualdad, por lo tanto, con el establecimiento de adecuados niveles de una igualdad material, como consecuencia lógica, se logra el ejercicio efectivo y real de la libertad ${ }^{11}$. Alexy cree que no hay dudas en que un individuo le entregue mayor importancia a la superación de su deficitaria situación que las libertades jurídicas, que debido a su situación defectiva no le sirven de nada y que, por lo tanto, se convierten en fórmulas meramente vacías ${ }^{12}$.

${ }^{8}$ Alexy, R., "Derechos Sociales Fundamentales", en Carbonell, M., Cruz Parcero, J.A. y Vázquez, R. (Comp.), Derechos sociales y derechos de las minorías [En línea] http://www.bibliojuridica.org/libros/4/1658/4. pdf, 2000, pp. 71-74, [Consulta: 12 de diciembre de 2008]. Celis Danzinger, G., "Los Derechos Económicos, Sociales y Culturales. Limitaciones y Proyecciones", en Nomos, Vol. 2, 2008, p. 78.

9 Böckenförde, E.W., Escritos sobre derechos fundamentales. Nomos Verlagsgesellschaft, Baden-Baden, 1993 , pp. 74-75.

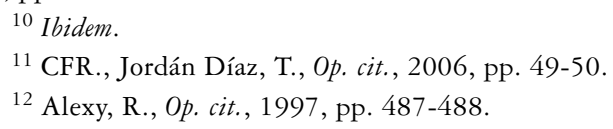


Estos autores, a pesar de sus ostensibles diferencias conceptuales sobre los derechos sociales $^{13}$, mantienen una tesis reduccionista en relación con una visión integral e inclusiva de los derechos sociales, vinculándose con el resto de los derechos fundamentales, toda vez que desconocer la categoría de los derechos sociales responde a criterios extrajurídicos, pues todos los derechos fundamentales, ya sean estos civiles y políticos o sociales, se pueden configurar como derechos de libertad fáctica o real. Es necesario señalar que todos los derechos fundamentales satisfacen, de alguna u otra manera, las necesidades básicas que permiten un disfrute de manera estable y sin intervenciones arbitrarias o abusivas por parte de un tercero (sea el Estado o un particular) de la autonomía individual. No existe una contradicción ni tampoco una supeditación iusfilosófica de los derechos sociales para con los derechos y libertades civiles y políticos, pues ambas categorías de derechos pueden ser observados como derechos de libertad e igualdad ${ }^{14}$.

\subsubsection{La necesidad e importancia como urgencia vinculados a la dignidad humana}

La fundamentación de los derechos sociales a partir del concepto de necesidad es desarrollado principalmente por Ernst Tugendhat, quien establece un criterio filosóficojurídico enmarcado en un Estado Social y Democrático de Derecho, con una profunda y ácida crítica a la concepción liberal de los derechos fundamentales.

Tugendhat fundamenta su tesis bajo dos argumentos, la libertad y la autonomía del individuo se dejan subsumir bajo los conceptos de necesidad y de derechos morales, y la libertad es una necesidad humana esencial, por tal motivo, debe protegerse y concebirse como un derecho moral ${ }^{15}$. Tugendhat cuestiona la fundamentación de los derechos sociales efectuada por Alexy al sostener que este se equivoca al establecer que los derechos sociales en su totalidad son derechos de libertad ampliados, pues para la conservación de la vida no deben darse únicamente condiciones externas, sino también capacidades propias; por tal motivo, no parece razonable asegurar una existencia humana digna de todas las personas en relación con los derechos humanos solamente mediante la ampliación del concepto de libertad ${ }^{16}$.

Bernal Pulido, siguiendo a Tugendhat, ha señalado que el sistema de derechos fundamentales no puede sostenerse sobre la presunción errada de que la sociedad está conformada enteramente por individuos capaces, autónomos y autosuficientes, y que además intervienen en condiciones de igualdad en la toma de decisiones políticas, es

13 Alexy es proclive a una concepción minimalista de los derechos sociales, en cambio Böckenförde se inscribe dentro de aquellos autores que señalan que los derechos sociales son disposiciones meramente programáticas, supeditadas al desarrollo por parte de la Administración Pública y el Legislador, y no por parte del Tribunal Constitucional, como sucede en el caso alemán. Alexy, R., Op. cit., 2000, pp. 67-70. Böckenförde, E.W., Op. cit., 1993, pp. 72-83.

${ }^{14}$ Pisarello, G., Los derechos sociales y sus garantías. Elementos para una reconstrucción, Trotta, Madrid, 2007, pp. 41-49.

15 Tugendhat, E., Lecciones sobre ética, Gedisa, Barcelona, 1997, p. 344.

${ }^{16}$ Arango, R., El Concepto de Derechos sociales fundamentales, Legis, Bogotá, 2005, p. 283. 
imperioso reconocer que el liberalismo presupone más individuos capaces de ser ciudadanos libres de los que existen en la práctica ${ }^{17}$.

Lo que realmente importa es reconocer que el hombre tiene determinadas necesidades que le son inherentes y cuya satisfacción es uno de los fines principales de la comunidad política, siendo que dichas necesidades fundamentan a los derechos sociales, los derechos de libertad y los derechos políticos, pues todas estas normas tienen la finalidad propia de satisfacer sus necesidades básicas y para sobrellevar una existencia digna. Por lo tanto, los derechos sociales deben ser considerados como fines en sí mismos ${ }^{18}$.

Siguiendo una lógica semejante, Rodolfo Arango establece una fundamentación de los derechos sociales a través del concepto de importancia como urgencia, el cual se deriva del alto grado de importancia que poseen los derechos fundamentales, incluyendo también a los derechos sociales ${ }^{19}$. Siguiendo este razonamiento, lo que resulta relevante es la urgencia dentro de una situación fáctica concreta para encontrarse plenamente justificada. El concepto de urgencia radica en la determinación del grado de importancia que debe contar todo derecho fundamental, siendo una ostensible ventaja, pues la urgencia es un criterio gradual y relativo ${ }^{20}$. De esta manera, la tesis de la urgencia rechaza un listado $a$ priori de derechos fundamentales, solamente ocurrirán trade offs entre libertad e igualdad, cuando la importancia de todas las posibles razones para posiciones iusfundamentales se tomen en serio, pues para analizar la vulneración de un derecho fundamental debe considerarse el grado de importancia de estos, pero esta solamente puede derivarse a través de la urgencia de la situación concreta para el individuo.

En el caso específico de los derechos sociales, la urgencia de la situación para el individuo se convierte en un criterio decisivo para la vulneración del derecho, toda vez que, generalmente, no es una acción la que se analiza sobre la base del principio de proporcionalidad $^{21}$, sino más bien una omisión como causa que origina la vulneración

${ }^{17}$ Bernal Pulido, C., "Fundamento, concepto y estructura de los derechos sociales. Una crítica a “¿Existen derechos sociales? de Fernando Atria”, en Discusiones (Publicaciones periódicas) [En línea], http:// descargas.cervantesvirtual.com/servlet/SirveObras/12937957558077187421624/015573.pdf?incr=1 Vol. 4, 2004, p. 110. [Consulta: 12 de diciembre de 2008].

18 Íbid, pp. 113-114.

19 Véase el número 2 del capítulo primero del libro de Arango, en donde se establece la definición y características de los derechos fundamentales, donde se analiza la noción de "alto grado de importancia". Arango, R., Op. cit., 2005, pp. 31-37.

${ }^{20}$ Arango, citando a Thomas Scalon, sostiene que desde el punto de vista de la filosofía moral, que en los argumentos morales la apelación a la urgencia relativa parece ser la apelación a un consenso en torno a lo mucho que las personas valoran ciertos beneficios, protecciones, etc. La estructura de tales argumentaciones consiste principalmente en sostener que cada persona acepta para sí que, digamos, ser protegida de ciertas consecuencias es más importante que disfrutar de otro beneficio. Véase Arango, R., Op. cit., 2005, p. 326.

21 Siguiendo a Barnes, señalamos que el principio de proporcionalidad, entendido de manera convencional y amplia, corresponde al principio constitucional en virtud del cual la intervención pública ha de ser "susceptible" de alcanzar la finalidad perseguida, "necesaria" o imprescindible al no haber otra medida menos restrictiva de la esfera de libertad de los ciudadanos (es decir, por ser el medio más suave y moderado de entre todos los posibles -ley del mínimo intervencionismo-) y "proporcional” en sentido estricto, es decir, "ponderada" o equilibrada por derivarse de aquella más beneficiosa o ventajosa para el interés general que perjuicios sobre otros bienes, valores o bienes en conflicto, en particular sobre los derechos y libertades. En 
del derecho, tornándose compleja su verificación. Por lo tanto, este principio debe complementarse con el concepto de urgencia en el caso de una omisión, ya sea efectuado por un particular o por el Estado ${ }^{22}$.

Ambas nociones que fundamentan la existencia de los derechos sociales, necesidad y urgencia, se vinculan directamente con la dignidad humana, concepto que sirve de fundamento no solo a los derechos civiles y políticos, sino también a los derechos sociales $^{23}$, el que normativamente ha estado vinculado con la satisfacción de aquellas necesidades que permiten perseguir libremente fines y planes de vida propios y participar en la construcción de la vida social. Es manifiesta la íntima relación de ambos conceptos con la dignidad humana, pues los derechos sociales significan, dentro de un estado democrático, una vinculación que va más allá de la consideración de ciertos derechos personalísimos adscritos directamente a una concepción liberal conservadora de los derechos fundamentales, que excluyen a otros derechos políticos y sociales. Por lo tanto, sin derechos sociales básicos, los civiles personalísimos corren el riesgo de verse vaciados en su contenido ${ }^{24}$.

Sin embargo, la noción de dignidad, incluyendo la idea de necesidad y urgencia, no es suficiente para fundamentar a los derechos sociales desde una manera particular, ya que esta noción sirve de explicación basal para todos los derechos fundamentales, y se encuentra establecido intrínsecamente en los derechos sociales. Solamente una estrecha concepción liberal conservadora puede deslindar el derecho a la igual dignidad de las personas de las necesidades básicas como la alimentación, el vestuario, la vivienda, la educación, la autoestima y, en general, la ausencia de daños evitables ${ }^{25}$.

\subsection{La igualdad material o sustancial}

Los derechos sociales tienen como una de sus características principales tratarse de derechos de igualdad, entendido en el sentido de igualdad material o sustancial, circunscribiéndose a la defensa de determinadas situaciones de discriminación normativa,

suma, pues, la acción estatal -en cualquiera de sus formas de expresión posibles (acto administrativo, norma, resolución judicial) - debe ser útil, necesaria y proporcionada. De tal manera, cada uno de los principios que lo integran requiere de un juicio o análisis diverso en su aplicación: el medio ha de ser idóneo en relación con el fin; necesario -el más moderado- respecto de todos los medios útiles, y proporcionada la ecuación costes-beneficios. Barnes, J., "Introducción al Principio de Proporcionalidad en el Derecho Comparado y Comunitario", en Revista de Administración Pública [En línea] http://www.cepc.es/rap/Frames.aspx?IDS=sflevg55 mopfj0ulcx ko3dnx_71298\&ART=1,23969,1994_135_495.PDF, Vol. 135, sept-dic 1994, p. 450. [Consulta: 14 de enero de 2009].

22 Arango, R., Op. cit., 2005, pp. 327-328.

23 Tomás Jordán, citando a Sánchez de la Torre y a Rodríguez Arana, señala que la dignidad humana como fundamento de los derechos sociales se puede observar desde una doble perspectiva: como exigencia programática para la realización de la dignidad personal, o como una clasificación de derechos que cumple funciones al servicio de dicha dignidad y de la libre determinación personal. Jordán Díaz, T., Op. cit., 2006 , p. 51.

${ }^{24}$ Pisarello, G., Op. cit., 2007, p. 40.

${ }^{25}$ Íbid, p. 41. 
a través del establecimiento de un régimen diferenciado que se concentra en las desigualdades fácticas ${ }^{26}$.

Se parte del correcto supuesto que la igualdad formal no es suficiente, pues esta se encuentra en una posición jurídica determinada que también se debe manifestar en su esfera sustancial o material. Y esto se logra mediante el reconocimiento de la diferencia como una realidad existente, y que afecta a sectores varios de la sociedad ${ }^{27}$. Toda vez que si se pretende establecer una igualdad nominal o formal, debe reconocerse efectivamente la desigualdad de facto. El argumento de igualdad parte de la premisa fáctica que existen personas o ciudadanos que se encuentran en una situación menesterosa frente a otros integrantes de la sociedad, por lo tanto, el derecho debe hacerse cargo de esta situación de hecho, lográndose a través del establecimiento constitucional de los derechos sociales ${ }^{28}$.

En este sentido, Tomás Jordán sostiene que hay un análisis de igualdad tanto justificativo como teleológico, ya que el recurso de existencia de los derechos sociales está determinado por las situaciones de carencia, y la finalidad intrínseca de esta categoría también está determinada por los contextos como situación futura a concretar, pudiendo hablarse de una fundamentación de doble carácter igualitario (igualdad como motivo e igualdad como fin ${ }^{29}$.

Partiendo de la base que el concepto de igualdad es un criterio netamente normativo $^{30}$ y no valorativo, junto con excluirse las identidades como las meras semejanzas ${ }^{31}$, la diferenciación se realiza a partir de situaciones de hecho respondiendo a la siguiente

${ }^{26}$ Prieto Sanchís, L., "Los derechos sociales y el principio de igualdad sustancial”, en Carbonell, M., Cruz Parcero, J.A. y Vázquez, R. (Comp), Derechos sociales y derechos de las minorías [En línea] http://www. bibliojuridica.org/libros/4/1658/3.pdf, 2000. [Consulta: 14 de enero de 2009]. Debemos recordar que la estructura que utiliza Prieto Sanchís para los derechos sociales posee un eminente carácter prestacional. Ver también Jordán Díaz, T., Op. cit., 2011, p. 554.

${ }^{27}$ Como señala Ferrajoli: Igualdad como norma, diferencia como hecho. Debe hacerse la salvedad que esta frase es extraída desde un artículo que tiene como finalidad hacerse cargo, por parte de Ferrajoli, de las críticas efectuadas por los movimientos feministas sobre la problemática de las discriminaciones. Ver Ferrajoli, L., Derechos y Garantías. La ley del más débil. Cuarta Edición, Trotta, Madrid, 2004, pp.73-80.

${ }^{28}$ Jordán Díaz, T., Op. cit., 2006, p. 47.

${ }^{29}$ Íbid, pp. 47-48.

${ }^{30}$ Contreras, García, Jordán y Villanueva, citando a Gavara de Cara, sostienen que: "El principio de igualdad tiene una doble configuración: como principio jurídico objetivo y como derecho subjetivo. Su carácter objetivo está relacionado con el imperativo que recae sobre los poderes públicos de proteger el contenido de este derecho, constituyéndose como ente primariamente obligado y limitado el poder legislativo, el cual deberá evitar la existencia de normas que establezcan tratos discriminatorios, abogando por la superación de las condiciones factuales de desigualdad en busca de igualdad sustancial o material”. Contreras Vásquez, P., García Pino, G., Jordán Díaz, T. y Villanueva Rojas, Á., "Informe en Derecho Presentando ante el Tribunal Constitucional en el Proceso de Inconstitucionalidad del Artículo 38 Ter de la Ley $\mathrm{N}^{\circ} 18.933$ ”, en Revista Estudios Constitucionales, Vol. $8 \mathrm{~N}^{\circ} 2,2010$, p. 650.

31 Prieto Sanchís, para ejemplificar esta situación, señala lo siguiente: “(...) nunca dos personas o situaciones vitales son iguales en todos los aspectos, los juicios de igualdad no parten nunca de la identidad, sino que son siempre juicios sobre una igualdad fáctica parcial. Pero como las personas son siempre iguales en ciertos aspectos y desiguales en otros, resulta que los juicios fácticos sobre igualdad-desigualdad parcial no nos dicen todavía nada acerca de si el tratamiento jurídico debe ser igual o desigual”. Prieto Sanchís, L., Op. cit., 2000, pp. 30-31. 
lógica: “(...) en las situaciones en que no hay desigualdad entre sujetos equivalentes no cabe la diferenciación, pero entre sujetos que se sitúen en posiciones desiguales y tal diferencia ubica a alguno de los actores en situación de precariedad material, existirán razones para disponer una diferenciación nominal a su favor ${ }^{32}$.

Pero este análisis o valoración conjunta de elementos fácticos de diferenciación sobre la base del criterio de razonabilidad implica que existe una violación del principio de igualdad cuando el tratamiento desigual esté desprovisto de una justificación objetiva y razonable; el principio de igualdad exige que las consecuencias jurídicas que se derivan de supuestos de hecho iguales, sean asimismo, iguales, debiendo considerarse iguales dos supuestos de hecho cuando el elemento diferenciador introducido por el legislador carece de relevancia para el fin perseguido en la norma ${ }^{33}$. Por lo tanto, el principio de igualdad se traduce en una exigencia de fundamentación racional del valor por parte de los juicios que son inexcusables a la hora de conectar determinada situación a una cierta consecuencia jurídica ${ }^{34}$.

Es importante destacar que las normas de desigualdades presentan dos peculiaridades, la primera es que funcionan siempre como un principio, pues, aunque haya razones para la desigualdad, siempre habrá alguna para la igualdad; lo que significa que proporcionará en todo caso razones prima facie, que han de combatir con principios opuestos. La segunda es que, así como la igualdad resulta obligada cuando no exista ningún motivo que permita el trato desigual, este último, en cambio, requiere que exista una razón suficiente que, valoradas todas las razones en pugna, ordene el tratamiento desigual ${ }^{35}$. En consecuencia, la desigualación o diferenciación jurídica se justifica cuando la corrección de las situaciones de desigualdad no se pueda lograr sin el trato diferenciado ${ }^{36}$.

En consideración a lo sostenido precedentemente, Jordán señala que los criterios de diferenciación y los derechos sociales tienen su origen en virtud al principio de igualdad y solidaridad, cuyo fundamento radica principalmente en los siguientes razonamientos: a) la igualdad como un valor objetivo en los Estados Constitucionales Democráticos, con especial énfasis en aquellos de corte social; b) la existencia de situaciones de desigualdad real o factual; c) la estructuración de una situación de contradicción entre los postulados

32 Añon Roig, M. J., "La contribución de los derechos sociales al vínculo social”, en Añon Roig, M. J. (et al.), El vínculo social: ciudadanía y cosmopolitismo, Tirant Lo Blanch, Valencia, 2002, citado en Jordán Díaz, T., Op. cit., 2006, p. 48.

33 Cfr. Prieto Sanchís, L., Op. cit., 2000, p. 30-31.

${ }^{34}$ Entonces, según Prieto Sanchís, habría violación legislativa del principio de igualdad y esta solo procede: a) cuando estamos en presencia de un tratamiento desigual, sin ninguna razón que lo permita, y b) cuando estamos en presencia de un tratamiento igual, habiendo una razón que lo impida. Por ello, un tratamiento desigual que no resulte arbitrario o carente de razón no significa que, contrario sensu, un tratamiento igual haya de reputarse arbitrario. Íbid, p. 34.

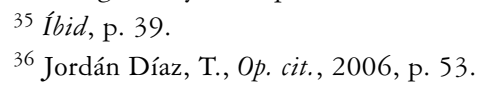


a) y b); y d) los derechos sociales se constituyen como instrumento de igualación o corrección y de eficacia de los mandatos constitucionales ${ }^{37}$.

Por lo tanto, mediante la constatación empírica de la realidad, y la incompleta comprensión de esta por parte del liberalismo y el conservadurismo en la articulación de fundamentos para los derechos fundamentales, y por ende, los derechos sociales, ha significado la estructuración, en el lenguaje de derechos, de las reivindicaciones sociales de grupos marginados o desaventajados que exigieron al poder político modificar rotundamente el rol de inhibición del Estado, tendiente a subsanar las ostensibles diferencias generadas dentro de la sociedad. En virtud a esta situación, el ordenamiento jurídico estableció la constitucionalización de los derechos sociales y la utilización de la diferenciación jurídica como un criterio válido para lograr tales fines.

Si queremos establecer una teoría de los derechos fundamentales que sea incluyente e inclusiva, debemos sostener que el principio de igualdad irradia no solo a los derechos sociales, sino también a los derechos y libertades civiles y políticas, en plena concordancia y armonía, y sin ningún criterio jerárquico que permita diferenciar entre unos u otros. Por lo tanto, es la justicia constitucional ${ }^{38}$ quien está obligada, dentro de un sistema democrático constitucional, de velar por la plena concordancia y ponderación de los derechos fundamentales, y en especial, aquellos derechos que tienen como norte la igualdad desde su perspectiva sustancial o material ${ }^{39}$.

${ }^{37}$ Jordán Díaz, T., Op. cit., 2006, pp. 52-53. Respecto de esta situación, es importante destacar que las medidas correctivas para disminuir la desigualdad, y obtener un mayor o menor grado de igualdad, corresponde a una decisión eminentemente supeditada a una decisión deliberativa por parte de los actores políticos. Dichas decisiones se encuentran influenciadas por el tipo de Estado, el régimen político y las opciones políticas ideológicas de los actores, toda vez que dichas diferencias permitirán establecer medidas de un mayor o menor corte social.

38 En Chile, la justicia constitucional se encuentra ejercida por el Tribunal Constitucional y los Tribunales Superiores de Justicia, estos son la Corte Suprema y las Cortes de Apelaciones. El Tribunal Constitucional se encuentra encargado de realizar un control preventivo y represivo de constitucionalidad, en virtud a las atribuciones contenidas en el art. 93 de la Constitución. A su vez, los Tribunales Superiores de Justicia chilenos poseen la facultad de conocer acciones procesales de naturaleza constitucional o legal, como el Recurso de Protección, el Recurso de Amparo y el Recurso de Amparo Económico, que versen sobre alguna vulneración de un derecho fundamental contenido en la Constitución.

${ }^{39}$ Para el caso chileno, Tomás Jordán ha sostenido que en el ámbito de los derechos sociales fundamentales el principio de subsidiariedad es insuficiente para la realización de los imperativos de respeto y promoción del artículo 5 inciso segundo de la Constitución, dentro de la relación Estado-persona en un contexto democrático y bajo criterios deliberativos, planteando directamente su reemplazo por el principio de contribución constitucional, ya que los bienes relacionados con estos derechos son eminentemente jurídico-sociales y no económicos o con una lógica de mercado, a diferencia de lo que ocurre con los derechos y libertades civiles y políticos. Dicho principio es definido como el imperativo categórico que establece el deber de los órganos públicos y a las personas de cooperar y colaborar conjuntamente hacia los fines que la Constitución les impone. De esta manera, se propone ubicar la relación entre la persona y el Estado dentro de una perspectiva social de Estado, en la búsqueda del bien común, donde el rol estatal no esté predefinido por un criterio extrajurídico e ideológico, siendo definido a dicho rol a través de una mayoría democrática y deliberativa, lo que permitirá cumplir en forma coherente con los deberes de promoción y respeto de los derechos sociales fundamentales, teniendo como elemento fundante a la persona humana en el centro del ordenamiento constitucional y al Estado como instrumento al servicio de esta. Jordán Díaz, T., Op. cit., 2011, pp. 553-573. 


\section{LA ESTRUCTURA DE LOS DERECHOS SOCIALES}

Se ha dado cuenta dentro de la doctrina constitucionalista que existe una diferencia irreconciliable entre la estructura de los derechos sociales con los derechos civiles y políticos, señalándose principalmente que los derechos sociales son derechos prestacionales, costosos y condicionados a la realidad económica de un país, poseen enunciados vagos e indeterminados que dificultan la determinación de los sujetos obligados y la conducta prescrita, junto con ser derechos delimitados a una colectividad, impide su tutela efectiva ante los órganos jurisdiccionales ${ }^{40}$.

También existe otra forma de explicar la estructuración de los derechos sociales de una manera distinta a la señalada precedentemente. Lo que se pretende hacer en esta parte es analizar diversas aristas referidas a la estructura de los derechos sociales, como lo relativo a un concepto amplio de derecho subjetivo; en segundo lugar, se estudiará la consideración de los derechos sociales como derechos individuales o colectivos para determinar al titular de los derechos sociales; en tercera instancia, se examinará al sujeto obligado o pasivo de las obligaciones derivadas de los enunciados normativos sobre derechos sociales. Para finalizar se verá si los derechos sociales corresponden a derechos de acción positiva o negativa, tomando una postura sobre la materia.

\subsection{Sobre el concepto de derecho subjetivo}

La noción de derecho subjetivo (derecho público subjetivo) fue elaborada por la dogmática alemana en el siglo XIX, respondiendo a la expresión del individualismo dentro del pensamiento positivista, siendo desarrollado fundamentalmente por George Jellinek a través de su teoría del estatus ${ }^{41}$ en el ámbito del derecho público, circunscribiendo a los derechos como límites ante el poder público en su conjunto, pero no afectando a las relaciones entre particulares ${ }^{42}$.

Fue Hans Kelsen quien desarrolló la noción "liberal-tradicional” de dicho concepto, sosteniendo que existe derecho subjetivo, en el sentido específico de la palabra, cuando entre las condiciones de la sanción figura una manifestación de voluntad, querella o acción judicial, emanada de un individuo lesionado en sus intereses por un acto ilícito. Solamente cuando una norma jurídica ubica así a un individuo en posición de defender sus intereses, se crea un derecho subjetivo a su favor ${ }^{43}$. Podemos sostener que el concepto

\footnotetext{
${ }^{40}$ Pisarello, G., Op. cit., 2007, p. 59.

41 Ver Jellinek, G., Teoría general del Estado, Fondo de Cultura Económica, Ciudad de México, 2000.

42 Peces-Barba, G., Op. cit., 1997, p. 27.

${ }^{43}$ Kelsen, H., Teoría Pura del Derecho, Cuarta Edición, Cuarta Reimpresión, Eudeba, Buenos Aires,
} 2005, p. 100. Cruz Parcero ha sostenido que Kelsen se refirió a la conceptualización de derecho subjetivo como si fuera en un "sentido técnico", cuando identifica a la acción o facultad del titular de recurrir a los órganos jurisdiccionales para exigir el cumplimiento de una obligación correlativa. Cruz Parcero, J.A., "Los Derechos Sociales como técnica de protección jurídica”, en Carbonell, M., Cruz Parcero, J.A. y Vázquez, R. (Comp.), Derechos sociales y derechos de las minorias [En línea] http://www.bibliojuridica.org/libros/4/1658/5. pdf, 2000, p. 92. [Consulta: 14 de enero de 2009]. 
del derecho subjetivo se encuentra fundado fuertemente en una visión individualista del Derecho, incluso así lo destaca Kelsen cuando sostiene que este concepto solo debe aplicarse dentro de los ordenamientos jurídicos capitalistas y construidos sobre la base de la propiedad privada, tomando en consideración principalmente a los intereses de índole privado $^{44}$; junto con destacar la importancia que cumple la posibilidad de obtener una sanción mediante un procedimiento ante tribunales para exigir el cumplimiento de una obligación correlativa como el elemento gravitante para identificar a un derecho subjetivo ${ }^{45}$.

Este concepto ha sido asimilado principalmente por las tesis "liberales-tradicionales" para los derechos y libertades civiles y políticas, señalándose que estos últimos corresponden a la categoría propiamente tal de derechos fundamentales, pues el desarrollo del primigenio liberalismo ilustrado sostuvo que los derechos y libertades civiles y políticas consisten en derechos anteriores al Estado y de defensa del individuo ante las posibles intervenciones estatales, llegando a considerarse incluso como absolutos, junto con poder ejercer los medios procesales respectivos para exigir el cumplimiento de las obligaciones derivadas de la norma jurídica, denotando un criterio más bien ideológico e historicista en sus formulaciones ${ }^{46}$. Según esta tesis, la categoría de derechos sociales no se relaciona con el concepto tradicional de derechos fundamentales, pues es una contradicción al sentido jurídico del término derecho subjetivo ${ }^{47}$, ya que los derechos

${ }^{44}$ Kelsen, H., Op. cit., 2008, p. 100.

45 En este mismo sentido se ha referido Ricardo Guastini, al señalar que un derecho es "verdadero" cuando cumple tres condiciones: a) son susceptibles de tutela jurisdiccional; b) pueden ser ejercidos o reivindicados frente a un sujeto determinado; c) su contenido está constituido por una obligación de conducta determinada. Guastini, R., Distinguiendo, Gedisa, Barcelona, 1999, pp. 185-189. En el caso chileno, Fernando Atria considera que el derecho subjetivo es la posición en la que se encuentra una persona con potestad para decidir si la obligación de otro será o no coactivamente exigida, claramente siguiendo la misma lógica señalada por el jurista italiano. Atria, F., “¿Existen derechos sociales?”, en Discusiones (Publicaciones periódicas) [En línea] http://descargas.cervantesvirtual.com/servlet/SirveObras/01826630549036114110035/015570. pdf? incr $=1$ Vol. 4, 2004, p. 22. [Consulta: 11 de enero de 2009].

46 En este aspecto, Pachot sostiene que: "Sin embargo, persistió en la doctrina académica alemana de entonces una marcada influencia del modelo liberal de interpretación de los derechos fundamentales, pretendiendo considerar exclusivamente como tales, y absolutos en consecuencia, aquellos derechos de libertad del individuo frente al Estado, es decir, aquellos derechos civiles y políticos, siendo considerados los demás derechos constitucionales como relativos, al no disfrutar del mismo grado de protección de los primeros, quedando excluidos de la categoría de fundamental los DESC y, en sentido general, relativizando su condición jurídica. Esta interpretación, condicionada además por el vacío jurisprudencial en torno a la identificación de los elementos definitorios de los derechos fundamentales, fue asumida por la doctrina académica, desde la cual se comenzaron a delimitar aquellas normas que contenían "auténticos" derechos fundamentales de aquellas otras que no los contenían”. Pachot, K., "A Propósito del Carácter Fundamental de los Derechos Económicos, Sociales y Culturales. Una Mirada desde la Doctrina Comparada y la Experiencia del Ordenamiento Jurídico Cubano”, en Revista Estudios Constitucionales, Vol. 8 No 1, 2010, p. 23.

${ }^{47}$ Fernando Atria parte de la tesis que los derechos sociales son un contrasentido si se intenta establecerlos dentro del sentido jurídico del concepto de derecho subjetivo. Para afirmar tal aseveración, Atria aplica un criterio historicista para señalar que los derechos y libertades civiles y políticas son anteriores al poder constituyente y justifican la formación de la comunidad política, siendo reivindicados como naturales, junto con ser el titular de estos únicamente el individuo. Además, agrega que la concepción socialista busca articular sus demandas a través del concepto de derecho subjetivo, sin embargo, los derechos sociales no 
sociales no contemplarían la posibilidad de exigir ante un órgano jurisdiccional el cumplimiento del deber contemplado ${ }^{48}$, porque los jueces se encontrarían inmiscuyendo en la esfera del Legislador y de la Administración, al inmiscuirse en temáticas relativas a políticas públicas ${ }^{49}$.

La visión kelseniana del concepto de derecho subjetivo ha sido criticada fuertemente por diversos sectores, señalándose que centrar la noción de derecho subjetivo en la exigibilidad de este responde a una visión reduccionista que confunde tener un derecho con tener una garantía ${ }^{50}$, además de responder a un criterio circular de lo que se entiende por exigibilidad, ya que las nociones procesales propias del sistema continental aparecen dentro del marco conceptual del liberalismo, que se enfocaba en el interés de los individuos, en el derecho de propiedad y en la actividad abstencionista del Estado, ante lo cual la respuesta lógica y automática es a desconocer completamente la justiciabilidad de los derechos sociales, si estos no se encuentran establecidos de igual forma que los derechos y libertades civiles y políticas ${ }^{51}$.

justificarían la existencia del Estado y de la comunidad política, y tampoco cumplen con los requisitos del concepto de derecho subjetivo, entendido de la forma que Atria lo hace. Atria, F., Op. cit., 2004, pp. 15-39. Se recomienda ver también lo sostenido por Atria, quien responde a las críticas efectuadas en esta materia por Carlos Bernal Pulido y Juan Antonio Cruz Parcero en Atria, F., "Replica: derecho y política a propósito de los derechos sociales", en Discusiones (Publicaciones periódicas) [En línea] http://descargas.cservantesvirtual. $\mathrm{com} / \mathrm{servlet} /$ SirveObras/06923896589547328537857/015574.pdf? incr $=1$

Vol. 4, 2004 pp. 145-176. [Consulta: 11 de enero de 2009].

48 José Ignacio Martínez delimita el carácter de derecho propiamente tal a si este es susceptible de ser justiciable por parte de los Tribunales de Justicia, llegando a señalar que: "Más concretamente, saber si algo es o no un derecho en sentido jurídico depende de su justiciabilidad, en el sentido de acción conducente a una decisión que permitirá amparar y proteger tal derecho frente a las acciones u omisiones de terceros". Martínez Estay, J.I., Op. cit., 2010, p. 152.

${ }^{49}$ Carlos Bernal Pulido y Tomás Jordán nos señalan que existen variadas teorías sobre los derechos sociales, indicándose que estos son "normas o disposiciones programáticas", "normas de fines del Estado", "poderes" hacia terceros o "mandatos constitucionales de optimización”, junto con ser derechos infraconstitucionales o de configuración legal. Bernal Pulido, C., Op. cit., 2004, pp. 118-133. Jordán Díaz, T., Op. cit., 2006, p. 36. Esta concepción es mayoritaria dentro de la doctrina constitucional chilena, pudiendo destacarse lo sostenido por Luz Bulnes quien sostiene que "(...) en la generalidad de los casos se trata de prestaciones o de programas políticos que en principio solo serían justiciables si son regulados por ley", como también "Se estimaron eminentemente programáticos. Se consideraban programas que se introducían en las Constituciones para ser implementadas por la ley, lo que significaba que para que pudieran exigirse por la vía judicial requerían de actuaciones del Estado". Bulnes Aldunate, L., "El Derecho a la Protección de la Salud en la Constitución de 1980”, en Gaceta Jurídica, Vol. 295, 2005. En este mismo sentido, José Ignacio Martínez Estay sostiene que "(...) por regla general los sociales recogen más bien principios, programas o aspiraciones político-sociales elevadas a nivel constitucional”, además señala "Dichas metas son antes que nada objetivos políticos, a los que el Derecho a lo más puede servir de instrumento”. Martínez Estay, J.I., "Lección Undécima. Los Derechos Sociales”, en Pereira Menault, A.C., Teoría Constitucional. Segunda Edición chilena. LexisNexis, 2006, pp. 305-306.

${ }^{50}$ Cruz Parcero, J.A., El lenguaje de los derechos: ensayo para una teoría estructural de los derechos, Trotta, Madrid, 2007, p. 78.

${ }^{51}$ Abramovich, V., y Courtis, C., Los derechos sociales como derechos exigibles, Trotta, Madrid, 2002, pp. 39-45. Siguiendo esta misma tesis, Pisarello sostiene que la doctrina en esta materia establece la exigibilidad como un todo o nada, no realizando las graduaciones necesarias que permitan distintos niveles de protección para los derechos fundamentales. Pisarello, G., Op. cit., 2007, pp. 88-89. 
Para profundizar aun más en las críticas hacia la noción reduccionista del concepto de derecho subjetivo, Ferrajoli manifiesta que dichas concepciones tienden a asimilar el concepto de derechos fundamentales con los derechos patrimoniales ${ }^{52}$, además de confundir la idea de tener un derecho con las garantías establecidas por las normas jurídicas, considerando que la exigibilidad de un derecho corresponde a una garantía secundaria de protección, elemento que no puede considerarse como fundamental a la hora de conceptualizar teóricamente la noción de derecho subjetivo, siendo la garantía primaria el deber originado de la relación jurídica para con el titular. En el caso de los derechos sociales, Ferrajoli señala que estos derechos deben ser considerados como derechos fundamentales, y que su problema de exigibilidad (garantía secundaria) radica en la existencia de un defecto en las instituciones obligadas a sancionar o a invalidar las violaciones a los derechos, siendo denominada como laguna secundaria, lo que no implica por ningún motivo que no sean considerados como derechos subjetivos ${ }^{53}$.

En contraposición a Kelsen se encuentra Alf Ross, quien ha sostenido que la noción de derecho subjetivo corresponde a un concepto meramente descriptivo, que debe dar cuenta de las consecuencias jurídicas derivadas de una relación jurídica que crea derecho, dando cuenta del derecho vigente dentro de un ordenamiento jurídico y su aplicación concreta $^{54}$. Ross estima que la noción de derecho subjetivo debe poseer dentro de su concepto las siguientes características:

52 Según Ferrajoli, existen cuatro diferencias que permiten rechazar esta asimilación: i) los derechos fundamentales son derechos universales referidos a sus titulares, mientras que los derechos patrimoniales son derechos singulares en el sentido que un titular de estos excluye a los demás; ii) los derechos fundamentales son derechos indisponibles, inalienables, intransigibles, personalísimos, a diferencia de los derechos patrimoniales que son derechos disponibles por esencia, alienables y negociables; iii) los derechos patrimoniales están destinados a ser constituidos, modificados y extinguidos por actos jurídicos, siendo predispuestos por normas, a diferencia de los derechos fundamentales que tienen su título inmediatamente de la ley, pues existe un mandato desde la constitución que les otorga el carácter de normas; iv) los derechos patrimoniales son horizontales, pues se generan en virtud a relaciones jurídicas entre particulares, en contraposición a los derechos fundamentales que generan relaciones verticales entre el individuo o la persona frente al Estado. Ferrajoli, L., Op. cit., 2000, pp. 29-35.

53 Íbid pp. 45-52. Adicionalmente, y citando a Freixes Sanjuán, Pachot plantea que: “(...) y con el ánimo de rescatar el valor fundamental de los DESC, se ha pronunciado en la propia doctrina Freixes Sanjuán, sosteniendo el deber de concederles, o más bien reconocerles, ese valor a todos los DESC, ya que no les falta protección jurídica y, aunque la que obtienen es menor que la que hubieran obtenido si la Constitución les hubiera otorgado la estructura de plenos derechos subjetivos, su estructura como orden de valores y acceso a determinadas y muy importantes garantías constitucionales les atribuyen carácter jurídico de derechos fundamentales, sin que quepa hacer distinción de rango a base de su efectividad inmediata o diferida. Pachot, K., Op. cit., 2010, p. 27.

${ }^{54}$ En palabras de Ross: “(...) hay que afirmar que el concepto de derecho subjetivo no tiene referencia semántica alguna. No designa fenómeno alguno de ningún tipo que esté insertado entre los hechos condicionantes y las consecuencias condicionadas; únicamente es un medio que hace posible (...) representar el contenido de un conjunto de normas jurídicas, a saber, aquellas que conectan cierta pluralidad disyuntiva de hechos condicionantes con cierta pluralidad acumulativa de consecuencias jurídicas. Ross, A., Sobre el derecho y la justicia, Tercera Edición, Primera Reimpresión, Eudeba, Buenos Aires, 2006, p. 215. 
- un sujeto de derecho, correspondiendo a una persona titular de una libertad o una potestad;

- el contenido del derecho, incluyendo la facultad que tiene el titular del derecho contra otros y cómo su potestad hace valer esta facultad, entendiendo que la potestad para iniciar algún tipo de procedimiento son accesorios a la facultad principal. La protección procesal del derecho no es más que otro aspecto del contenido del derecho. Ross distingue entre protección estática, la cual corresponde a las sanciones que pueden ser aplicadas en caso de violación del derecho subjetivo, y la protección dinámica, que regula la competencia entre diversos sucesores en conflicto, cada uno de los cuales tiene una legítima expectativa;

- el objeto del derecho subjetivo, que consiste en la plena determinación del contenido de un derecho in rem concreto incluyendo el objeto físico en relación con el titular del derecho que tiene una facultad de goce exclusiva ${ }^{55}$.

Por otro lado, Arango sostiene como tesis que los derechos sociales pueden ser concebidos perfectamente como derechos subjetivos, argumentando que la supuesta imposibilidad de conciliación entre una y otra noción depende exclusivamente de la claridad conceptual sobre dicha discusión. Arango define al derecho subjetivo como "el poder legal reconocido a un sujeto por medio de una norma legal, para la persecución de intereses propios mediante la exigencia a otro de hacer, permitir u omitir algo" 56 . De dicha definición se deben destacar tres aspectos que se caracterizan por funcionar de manera copulativa, siendo las siguientes:

- la norma jurídica: siendo expresada en un enunciado normativo, la cual puede formularse mediante una oración donde se declare que una acción es ordenada, prohibida o permitida. Una norma expresada de la forma de un enunciado normativo es una norma jurídica cuando su cumplimiento puede ser forzado por el poder estatal legítimo;

- una obligación jurídica: no existe un derecho subjetivo sin una obligación correlativa que obligue a otro a hacer o dejar de hacer algo, sin embargo, no debe entenderse la correlación como una relación entre derecho y obligación de manera única, pues existen normas que no mantienen dicha relación ${ }^{57}$.

- una posición jurídica: corresponde al poder jurídico reconocido en una norma jurídica e involucra el interés de un sujeto cuya protección se desea o se persiga jurídicamente, no obstante lo anterior, la exigibilidad no es una condición necesaria para la existencia de un derecho subjetivo, las razones para la existencia de un

${ }^{55}$ Ross, A., Op. cit., 2006, pp. 225-228. A su vez, Ferrajoli entiende como derecho subjetivo "cualquier expectativa positiva o negativa adscrita a un sujeto por una norma jurídica”. Ferrajoli, L., Op. cit., 2000 , p. 19.

56 Arango, R., Op. cit., 2005, pp. 8-9.

${ }^{57}$ Arango da como ejemplo en este caso aquellas normas de derecho público que imponen deberes a las autoridades públicas sin que exista un derecho subjetivo para los beneficiarios a exigir el cumplimiento de los deberes, como es el caso de las políticas públicas de fomento o subsidios. Arango, R., Op. cit., 2005, p. 12. 
derecho son condiciones necesarias de los mismos, mientras que los derechos son condiciones necesarias para su exigibilidad ${ }^{58}$.

Para este autor, los derechos subjetivos pueden configurarse como libertades 59 , derechos a algo ${ }^{60}$ o competencias, ya que estas tres formas poseen la estructura de una norma jurídica, una obligación jurídica y una posición jurídica. Por lo tanto, los derechos sociales pueden ser considerados, dentro de la noción de derecho subjetivo, todos aquellos que comprenden las tres mencionadas características junto al "alto grado de importancia”, elemento fundamental en todo derecho fundamental según lo señalado por Alexy ${ }^{61}$ (ya sean estos de defensa o prestación), más el carácter de derechos generales positivos establecidos en forma explícita o implícita en las constituciones ${ }^{62}$.

Siguiendo a Gavara de Cara, sostenemos que los derechos fundamentales deben ser entendidos como relaciones jurídicas, lo cual permite centrar el análisis de estos en tres conceptos primordiales que deben ser analizados para cada derecho en específico, correspondiendo a: i) el sujeto activo o titular de la determinada relación jurídica que asume la facultad jurídica de la relación; ii) el sujeto pasivo o destinatario de la relación posee el deber jurídico de la relación; y iii) el objeto de un derecho fundamental, comprendiendo una acción negativa que consiste en una abstención o una acción positiva que implica un hacer ${ }^{63}$.

A continuación se procede a analizar estos conceptos dentro de los derechos sociales, para determinar de manera teórica y general sus respectivos alcances.

\subsection{El titular de los derechos sociales. Derechos individuales o derechos colectivos}

Se ha sostenido por un sector de la doctrina que los derechos sociales son derechos circunscritos a un grupo de personas o a una colectividad determinada, una minoría o a la ciudadanía ${ }^{64}$. Generalmente esta tesis ha sido extrapolada de tal manera que los

58 Íbid pp. 9-22.

59 El portador (a) de la libertad acción (L), el obligado (b) y el objeto de la libertad (G).

${ }^{60}$ El portador del derecho (a) tienen derecho (D) a una acción (G) respecto del obligado (b).

61 Ver infra número 5.

62 Pudiendo resumirse de la siguiente manera: los derechos sociales se encuentran establecidos en una norma jurídica, generado una obligación jurídica, originando una posición jurídica iusfundamental, con un alto grado de importancia y siendo un derecho general positivo. Arango, R., Op. cit., 2005, pp. 31-46.

63 Gavara de Cara, J.C., "Los Derechos Fundamentales", en Gavara de Cara, J.C. (Ed.), Desarrollo, Rasgos de Identidad y Valorización en el XXV Aniversario (1978-2003), J. M. Bosch Editor - Institut de Ciences Politiques i Sociales, 2004, pp. 32-36. Se recomienda revisar la presentación crítica que realiza Daniel Riveros en relación con la jurisprudencia de la Corte Constitucional de Colombia, centrándose en los mismos aspectos mencionados anteriormente. Riveros Pardo, D., "Los derechos económicos, sociales y culturales como derechos subjetivos: una visión estructural”, en Revista Derecho del Estado, Vol. 24, 2010, pp. 29-43.

${ }^{64}$ Luigi Ferrajoli se ha referido a esta temática de manera general, criticando lo afirmado por T. H. Marshall, quien sostiene que los titulares de derechos fundamentales (y por ende de los derechos sociales) son los ciudadanos, pues dicha conceptualización puede generar una aplicación regresiva de la universalidad de los derechos, motivado principalmente por los actuales problemas de inmigración desde los sectores pobres 
derechos y libertades civiles y políticos aparecen definidos como derechos individuales por excelencia ${ }^{65}$.

Al respecto, los derechos sociales no pueden ser considerados como derechos colectivos, pues el reconocimiento de estos derechos a favor de un colectivo no se debe a la pertenencia de alguien a un determinado grupo de individuos, si fuera lo contrario se estaría atentando a la autonomía del individuo y discriminando a quienes no pertenecen a una colectividad, limitando el carácter universal de los derechos sociales ${ }^{66}$.

Señala Arango que los derechos sociales son derechos individuales, pues los primeros pertenecen a la categoría de derecho subjetivo, siendo esta noción eminentemente individual, por ende, los derechos sociales son derechos individuales ${ }^{67}$. Los derechos sociales son derechos delimitados en forma exclusiva al individuo, pues estos tienen como fundamento el principio de igualdad material o sustantiva, permitiendo satisfacer las necesidades básicas de aquellos individuos que se encuentran en una situación de carencia dentro de la sociedad, ya sea en ámbitos como salud, educación, trabajo, previsión social, etc. Es el sujeto individual el que exige el cumplimiento efectivo del derecho social, si se ubica dentro de la situación de carestía en la sociedad haciendo valer su derecho, ya sea ante el Estado o un tercero, por tanto, al proceder la vulneración de un derecho social queda de manifiesto que el individuo se ve directamente afectado y se le reconoce posteriormente su conculcación.

Esta situación se puede ejemplificar según lo señalado por Tomás Jordán, quien entrega el siguiente ejemplo: “(...) si un trabajador es despedido injustamente o no se cumplen a su respecto las obligaciones previsionales deberíamos entender que el sujeto vulnerado es toda la categoría, conclusión a la que, sin embargo, no se arriba ni resulta plausible" 68 .

del mundo hacia los países más desarrollados. Ferrajoli, L., Op. cit., 2000, pp. 40-44. Siguiendo la misma lógica encontramos a Arango, quien ha señalado que "La restricción del concepto de derechos fundamentales a los ciudadanos nacionales se revela injustificada, porque la pertenencia a una comunidad nacional o a un grupo social no es razón suficiente ni necesaria para limitar la titularidad de derechos a acciones fácticas del Estado (derechos sociales) a un grupo cerrado de personas". Arango, R., Op. cit., 2005, p. 68.

${ }^{65}$ Martínez Estay nos entrega un claro ejemplo de esta argumentación, al sostener que "Pero su propia finalidad determina que la titularidad de estos derechos vaya unida a una cierta condición: los derechos sociales son derechos de trabajadores, de cesantes, de menesterosos, de enfermos, de jóvenes, de los sin casa. La excepción sería el derecho al medio ambiente descontaminado, cuya titularidad corresponde a toda la sociedad. Esta es una diferencia importante respecto de los derechos y libertades clásicos. Recuérdese que estos emanan de la propia naturaleza humana, por lo cual todos somos titulares de ellos. Martínez Estay, J.I. Op. cit., 2010, p. 132. A su vez, Pisarello sostiene que dicha idea debe ser desestimada, toda vez que perfectamente los derechos y libertades civiles y políticas pueden ser ejercidas por colectividades tales como los sindicatos u otras colectividades, etc. Junto con señalar que en los orígenes del constitucionalismo social, los derechos sociales fueron articulados para el trabajador. Por lo tanto, se puede sostener que ante la tesis de la oposición radical entre los derechos sociales y los derechos y libertades civiles y políticas se debe pensar que ambas categorías de derechos poseen una vertiente personal como colectiva. Como derechos potencialmente universales y como derechos vinculados a grupos concretos. Pisarello, G., Op. cit., 2007, pp. 72-75.

${ }^{66}$ Arango, R., Op. cit., 2005, p. 90. Ver también Jordán Díaz, T., Op. cit., 2006, pp. 54-55.

${ }^{67}$ Íbid, p. 60.

${ }^{68}$ Jordán Díaz, T., Op. cit., 2006, pp. 55-56. 
En idéntico sentido argumenta Daniel Riveros, al sostener que los derechos sociales no buscan proteger intereses colectivos, sino que individuales; y que por técnica legislativa se ha clasificado a la población en determinados grupos colectivos. En consecuencia: “(...) la titularidad de los derechos sociales debe estar asignada a todo miembro de la especie humana, singularizado, que se encuentre en una situación en la cual no pueda satisfacer por sí mismo sus necesidades" ${ }^{69}$. Por lo tanto, un sindicato que negocia colectivamente, un grupo de apoderados que reclaman por la mala calidad de la educación en un colegio en el que estudian sus hijos, o un grupo de personas enfermas de VIH que solicitan medicamentos para continuar con su tratamiento, no demandan pensando en el interés general abstracto de la sociedad, o del grupo particular en que se encuentran por la situación de necesidad que experimentan, sino en su propio beneficio, ya que los derechos sociales ofrecen cobertura a intereses específicos y determinados de los individuos afectados ${ }^{70}$.

\subsection{El sujeto pasivo en los derechos sociales. El Estado y los particulares como sujetos obligados}

Los derechos sociales obligan en forma primaria al Estado y a sus organismos, y en virtud a la eficacia horizontal de los derechos fundamentales, a los particulares. En este sentido, el Estado se encuentra obligado no solo a reconocer o promover derechos sociales, sino también a generar los mecanismos suficientes de respeto y protección de estos derechos ${ }^{71}$, ya sea a través de acciones positivas o negativas, tendientes a corregir la desigualdad material dentro de la comunidad $^{72}$.

Cuando se habla del Estado como sujeto obligado debe entenderse que se incluye al ejecutivo, como también al legislador y el poder judicial, solamente una visión sumamente restrictiva de los derechos delimitaría en forma exclusiva el cumplimiento de las obligaciones jurídicas al poder ejecutivo o al poder judicial en forma única. En el caso del legislador, debe entenderse que este se encuentra obligado a desarrollar las disposiciones constitucionales que versan sobre derechos sociales por medio de leyes elaboradas a raíz del proceso de deliberación pública que permitan su desarrollo en sede legal, junto con generar los recursos procesales para exigir su cumplimiento; el ejecutivo se encuentra obligado respecto de todos los derechos fundamentales, por ende, a los derechos sociales, significando que las decisiones deben ser tomadas por la autoridad interpretando y aplicando las normas jurídicas constitucionales referidas a dichos derechos; por último,

${ }^{69}$ Riveros Pardo, D., Op. cit., 2010, pp. 34-37.

${ }^{70}$ Por lo tanto, no se puede exigir al sindicato, al grupo de apoderados o a los portadores del VIH que atenúen sus demandas porque un supuesto deber de solidaridad con otros en situación parecida impida que se les satisfagan completamente sus demandas. López Fernández, D. Los Derechos de las Personas: La Fuerza de la Democracia. Ediciones Universidad Alberto Hurtado, 2009, pp. 22-23.

71 Abramovich, V. y Courtis, C., Op. cit., 2002, p. 29.

72 Jordán Díaz, T., Op. cit., 2006, p. 56. Riveros escribe que debe tenerse en cuenta las vulneraciones que podrían realizar los particulares que se ubican en situaciones de privilegios, ocasionando incluso abusos de poder, en términos similares a los que podría incurrir el Estado”. Riveros Pardo, D., Op. cit., 2010, pp. 37-38. 
el poder judicial también se encuentra obligado a velar por los derechos sociales al interpretar y aplicar las leyes en virtud a la Constitución y las disposiciones constitucionales sobre derechos sociales contenidas en la norma fundamental ${ }^{73}$.

En el caso de los particulares, se ha sostenido que estos también se encuentran obligados, por la aplicación de la eficacia horizontal de los derechos fundamentales, a cumplir con las obligaciones contenidas en las normas que contemplan derechos sociales, graficándose en la fórmula planteada por Pablo Contreras, quien sostiene que si un Derecho $D$ se aplica a una relación iusfundamental $x$, compuesta por los individuos privados $a$ y $b$, entonces $a$ tiene un $D$ frente a $b^{74}$, por lo que no importa determinar si $b$ es el Estado o un particular.

Esta tesis parte de la premisa que los derechos fundamentales poseen un carácter objetivo que irradia a las relaciones jurídicas entre los particulares, lo que se ha denominado como la constitucionalización del derecho privado ${ }^{75}$. Además, debe entenderse que una relación entre privados que verse sobre derechos sociales no es una relación estrictamente privada, sino que debe respetar el contenido esencial ${ }^{76}$ del derecho social en cuestión ${ }^{77}$.

En el contexto chileno, la Constitución reconoce expresamente la aplicabilidad de la eficacia horizontal de los derechos fundamentales en nuestro ordenamiento jurídico, específicamente en el artículo 6 inciso segundo ${ }^{78}$ al señalarse que toda persona (incluso

73 Arango, R., Op. cit., 2005, pp. 95-99.

${ }^{74}$ Contreras también explica la diferencia existente entre la eficacia horizontal inmediata o directa y la eficacia horizontal mediata o indirecta, la cual radica en si las normas sobre derechos fundamentales se aplican directamente en consideración a su carácter vinculante, o si estas sirven de parámetro a la hora de interpretar y analizar las normas de derecho privado. Contreras, P., Poder Privado y Derechos. Eficacia horizontal y Ponderación de los Derechos Fundamentales. Ediciones Universidad Alberto Hurtado, 2009, pp. 32-40.

${ }^{75}$ En este sentido, las relaciones entre particulares que versen sobre derechos sociales deben considerarse como relaciones de fundamentalidad, por lo tanto, la autonomía de la voluntad se encuentra limitada por mandato expreso de la Constitución por el contenido de los derechos fundamentales, toda vez que los derechos fundamentales rigen tanto para el ámbito público como privado de igual manera. Jordán Díaz, T., Op. cit., 2008, pp. 270-274.

76 Para una idea clara de lo que se entiende por contenido esencial de los derechos fundamentales se recomienda ver a Parejo Alfonso, L., "El Contenido Esencial de los Derechos Fundamentales en la Jurisprudencia Constitucional; a propósito de la Sentencia del Tribunal Constitucional de 8 de abril de 1981", en Revista Española de Derecho Constitucional [En línea] http://www.cepc.es/rap/Publicaciones/Revistas/6/REDC_003_169. pdf, Vol. 3, 1981 [consulta: 10 octubre de 2008].

77 Jordán Díaz, T., Op. cit., 2006, pp. 56-57. Desde una postura más restringida, Arango sostiene que solamente el Estado es el obligado para velar por el cumplimiento de los derechos sociales, y que los particulares se encontrarían obligados, si es que desarrollan alguna función pública como en salud o en educación, pero desconoce las relaciones entre particulares que se originan principalmente en el ámbito laboral. Arango, R., Op. cit., 2005, pp. 99-107.

78 Artículo 6, inciso segundo.- "Los preceptos de esta Constitución obligan tanto a los titulares o integrantes de dichos órganos como a toda persona, institución o grupo”. Gabriel Celis señala en este punto que: "En consecuencia, toda la preceptiva constitucional, inclusive los derechos sociales fundamentales, adquieren operatividad plena o directa, en un sentido doble, esto es, primero frente a los poderes públicos y luego respecto de los particulares. Opera así una vinculación inmediata de los órganos del Estado y de los particulares por los derechos humanos. (...) Ahora bien, respecto de los particulares el principio de vinculación 
las personas jurídicas) se encuentra obligada a los preceptos de la Constitución, y el artículo 20 relativo al Recurso de Protección ${ }^{79}$, pues no se delimita de manera explícita el sujeto que pudiere privar, perturbar o amenazar el ejercicio legítimo de un derecho fundamental contemplado en el catálogo del mismo artículo (salvo en el caso del derecho a un medio ambiente libre de contaminación donde la Constitución hace una referencia explícita a la persona), ya sea a través de una acción u omisión que pudiese realizar el Estado por medio de sus organismos, un grupo, una persona natural o una persona jurídica, derivado de una interpretación constitucional amplia y finalista sobre esta materia.

\subsection{El objeto de los derechos sociales. Derechos de libertad o derechos de prestación}

Respecto del objeto de los derechos sociales, una parte de la doctrina constitucionalista ha señalado que estos corresponden a derechos prestacionales y costosos, restringiendo estructuralmente a los derechos sociales como acciones positivas realizadas por el Estado, contraponiéndose a los derechos y libertades civiles y políticos, los cuales aparecen como derechos de actuación negativa y no onerosos ${ }^{80}$.

Estas consideraciones han generando una profusa crítica al respecto, pues se ha sostenido por diversos autores que mantener una división estructural como la señalada anteriormente responde más bien a concepciones sesgadas del funcionamiento del Estado, siguiendo una lógica decimonónica basada en el rol abstencionista del Estado, y una

directa de la Constitución se refleja en la denominada eficacia horizontal, siendo inmediatamente aplicable a las relaciones jurídicas entre privados”. Celis Danzinger, G., Op. cit., 2008, p. 85.

${ }^{79}$ Artículo 20.- "El que por causa de actos u omisiones arbitrarias o ilegales sufre privación, perturbación o amenaza en el legítimo ejercicio de los derechos y garantías establecidos en el artículo 19, números $1^{\circ}$, $2^{\circ}, 3^{\circ}$ inciso cuarto, $4^{\circ}, 5^{\circ}, 6^{\circ}, 9^{\circ}$ inciso final, $11^{\circ}, 12^{\circ}, 13^{\circ}, 15^{\circ}, 16^{\circ}$ en lo relativo a la libertad de trabajo y al derecho a su libre elección y libre contratación, y a lo establecido en el inciso cuarto, $19^{\circ}, 21^{\circ}, 22^{\circ}$, $23^{\circ}, 24^{\circ}$, y $25^{\circ}$ podrá ocurrir por sí o por cualquiera a su nombre, a la Corte de Apelaciones respectiva, la que adoptará de inmediato las providencias que juzgue necesarias para restablecer el imperio del derecho y asegurar la debida protección del afectado, sin perjuicio de los demás derechos que pueda hacer valer ante la autoridad o los tribunales correspondientes. Procederá, también, el recurso de protección en el caso del $\mathrm{N}^{\circ} 8^{\circ}$ del artículo 19 , cuando el derecho a vivir en un medio ambiente libre de contaminación sea afectado por un acto u omisión ilegal imputable a una persona determinada".

${ }^{80}$ En este sentido, Arango ha señalado que los derechos sociales únicamente derivan en acciones positivas fácticas, al poseer un contenido indeterminado, las cuales pueden realizarse a través de acciones diversas y titulares de las obligaciones en que se concreta. Arango, R., Op. cit., 2005, pp. 110-112. Cruz Parcero se manifiesta en la misma lógica de Alexy, al referirse a los derechos sociales como derechos prestacionales en sentido estricto, expresa que la dimensión prestacional resalta el carácter económico de los derechos sociales, para cuya satisfacción es necesaria una transferencia de recursos desde los sectores más acomodados a los más necesitados, generando fuertes reticencias de aquellos cuando se pretende garantizarlos judicialmente. Cruz Parcero, J.A., Op. cit., 2008, pp. 91-96. Ver también Alexy, R., Op. cit. 2000, pp. 78-85. José Ignacio Martínez afirma que los derechos sociales corresponden fundamentalmente en prestaciones, salvo los derechos sociales derivados del ámbito laboral, como el derecho a huelga, el derecho a la negociación colectiva y el derecho de sindicación, los cuales serían una manifestación de los derechos y libertades clásicos en las relaciones laborales, por lo que podrían estructurarse como obligaciones negativas. Martínez Estay, J.I., Op. cit., 2010, pp. 130-132. Diferenciando en este aspecto, Ansuátegui denomina esta explicación como el problema estructural y económico. Ansuátegui Roig, F., Op. cit., 2010, pp. 57-64. 
visión restrictiva de los derechos fundamentales, junto con establecerse un modelo de construcción social excesivamente limitado ${ }^{81}$.

Contraponiéndose a tales argumentaciones, se ha afirmado por varios autores que los derechos sociales y los derechos y libertades civiles y políticos se configuran no solo como acciones negativas, sino también en acciones positivas, es decir, en una estructura heterogénea o bidimensional, a diferencia de la anterior concepción homogénea y excluyente de los derechos fundamentales ${ }^{82}$. Esta concepción parte de la base de señalar que todos los derechos fundamentales implican la necesidad de realizar actuaciones positivas del Estado para crear las debidas condiciones que permitan el pleno desarrollo y ejercicio de los derechos dentro de una sociedad democrática, pero también derivan en obligaciones negativas de abstención o no intervención por parte de los órganos estatales ante una posible vulneración de un derecho social. Por tanto, todos los derechos fundamentales, sean estos derechos y libertades civiles y políticos, generan una dimensión distributiva dentro de la sociedad ${ }^{83}$.

81 Abramovich, V. y Courtis, C., Op. cit., 2002, p. 23. En sentido semejante, Nash indica que "Una interpretación restrictiva en esta materia (que mire solo el componente de abstención en materia de derechos fundamentales) lleva al incumplimiento de uno de los objetivos que tiene la consagración de los derechos fundamentales, cual es, lograr su pleno goce y ejercicio en una sociedad democrática entendida como una empresa colectiva de cooperación. (...) Por tanto, la efectividad está vinculada directamente con una visión compleja del contenido de los derechos fundamentales. Lo que supone también que las medidas para cumplir con dichas obligaciones prestacionales deben reunir requisitos que permitan alcanzar el fin perseguido y, además, estas medidas deben ser objeto de un real control democrático". Nash Rojas, C., "Los Derechos Económicos, Sociales y Culturales y la Justicia Constitucional Latinoamericana: Tendencias Jurisprudenciales", en Revista Estudios Constitucionales, Vol. 9 N $^{\circ} 1,2011$, p. 99.

${ }^{82}$ Jordán Díaz, T., Op. cit., 2006, pp. 40-43. Nash se refiere como obligaciones de contenido complejo. Nash Rojas, C., Op. cit., 2011, pp. 72 y 98. Baldessarre sigue la misma lógica, al afirmar que "(..) en el nuevo cuadro constitucional, ya no es sostenible el postulado inicial de la teoría apenas criticada, es decir, la contraposición de los derechos sociales a los derechos de libertad basada en la objeción que solo los primeros requieren prestaciones positivas (por parte del Estado), mientras los otros comportan solamente un deber de respeto y de abstención (siempre por parte del Estado)”. Baldesarre, A., Los derechos sociales, Serie de Teoría Jurídica y Filosofía del Derecho, Universidad Externado de Colombia, Bogotá, Colombia. 2001, pp. 38-42.

${ }^{83}$ A modo de ejemplo, Abramovich y Courtis señalan que “(...) el respeto de derechos tales como el debido proceso, el acceso a la justicia, el derecho a casarse, el derecho de asociación, el derecho de elegir y ser elegido, suponen la creación de las respectivas condiciones institucionales por parte del Estado (existencia y mantenimiento de tribunales, establecimiento de normas y registros que hagan jurídicamente relevante la decisión nupcial o el acto de asociación, convocatoria a elecciones, organización de un sistema de partidos políticos, etc.) (...) En síntesis, la estructura de los derechos civiles y políticos pueden ser caracterizadas como un complejo de obligaciones negativas y positivas por parte del Estado: obligación de abstenerse de actuar en ciertos ámbitos y de realizar una serie de funciones, a efectos de garantizar el goce de la autonomía individual e impedir su afectación por otros particulares". A su vez, los citados autores expresan que "Puede reconocerse que la faceta más viable de los derechos económicos, sociales y culturales son las obligaciones de hacer, y es por ello que a veces se los denomina derechos-prestación. Sin embargo, no resulta difícil descubrir cuando se observa la estructura de estos derechos la existencia concomitante de obligaciones de no hacer: el derecho a la salud conlleva la obligación estatal de no dañar la salud; el derecho a la educación supone la obligación de no empeorar la educación (...)”. Abramovich, V. y Courtis, C., Op. cit., 2002, pp. 21-27. Ver también Baldesarre, A., Op. cit., 2001, pp. 183-207. Pisarello, G., Op. cit., 2007, pp. 60-61. Celis Danzinger, G., Op. cit., 2008, p. 82. 
De tal argumentación se deriva que los derechos fundamentales implican una serie de obligaciones a los poderes públicos y los particulares, como obligaciones negativas de respeto $^{84}$ y obligaciones positivas de promoción y satisfacción, pasando a obligaciones de protección ante la conculcación de un derecho, ya sea por una acción u omisión de un agente estatal o particular ${ }^{85}$.

\section{Conclusiones}

Se ha procedido a analizar una serie de temáticas de suma importancia vinculada a los derechos sociales, como el valor que fundamenta la existencia de estos, la estructura sobre los derechos sociales y los derechos fundamentales en general, junto con la titularidad, el sujeto pasivo y el objeto de los derechos sociales.

La igualdad, en su vertiente material o sustancial, es el principio cardinal que fundamenta a los derechos sociales, por sobre la libertad fáctica y otros conceptos teóricos como la necesidad y la urgencia, ambos vigorizados por el principio de la dignidad humana. El principio de igualdad material parte de la base que dentro de nuestras sociedades modernas existen grupos de personas que se encuentran más afectados que el resto, teniendo importantes necesidades en salud, educación, vivienda, etc., que alteran fuertemente su desarrollo individual. El constitucionalismo social ha decidido elevar y proteger con rango constitucional aquellas diferencias normativas dentro del ordenamiento jurídico a través de los derechos sociales, permitiendo a las personas que por motivos fácticos pertenecen a los grupos más necesitados contar con las oportunidades necesarias para desenvolverse plenamente en la comunidad.

Al razonar sobre la estructura de los derechos sociales, no nos centramos en el concepto tradicional del derecho subjetivo que basa su análisis en la exigibilidad de estos ante los órganos jurisdiccionales, sino que partimos aceptando que la noción de derecho subjetivo comprende una relación jurídica centrada principalmente en la existencia de

${ }^{84}$ Claudio Nash delimita el significado de la obligación de respeto al indicar que esta “(...) consiste en cumplir directamente la conducta establecida en cada norma convencional, ya sea absteniéndose de actuar o dando una prestación. El contenido de la obligación estará definido, en consecuencia, a partir del mandato normativo del derecho o libertad concreta. Entre las medidas que debe adoptar el Estado pata respetar dicho mandato normativo se encuentran las acciones de cumplimiento, que pueden ser positivas (implican una actividad de prestación) y/o negativas (que implican una actividad de abstención) y estarán determinadas por cada derecho o libertad". Nash Rojas, C., Op. cit., 2011, p. 67.

${ }^{85}$ Pisarello, G., Op. cit., 2007, pp. 61-62. Nash Rojas, C., Op. cit., 2011, p. 102. A su vez, Riveros clasifica las obligaciones en (i) respetar, que implica el deber de abstenerse de interferir, obstaculizar o impedir el ejercicio de los derechos; (ii) proteger, adoptando las medidas necesarias a las circunstancias razonables para asegurar el ejercicio de los derechos e impedir la interferencia que podrían realizar terceros; (iii) cumplir, implica el reconocimiento de los derechos en el respectivo ordenamiento jurídico, adoptando las medidas o políticas necesarias para la satisfacción de estos; (iv) facilitar, que conlleva el deber de efectuar actividades que permitan fortalecer el acceso y/o disfrute de los derechos a las personas; y, por último, (v) proporcionar, asegurando al titular de los derechos que acceda al bien protegido de un derecho cuando un grupo o individuo no puede disfrutar del mismo. Riveros Pardo, D., Op. cit., 2010, p. 41. 
un sujeto de derecho, con un contenido del derecho y el objeto de este, ubicando a la exigibilidad en un rol secundario dentro de un concepto amplio del derecho subjetivo.

El titular de los derechos sociales corresponde exclusivamente al individuo y no a la comunidad o un grupo homogéneo determinado, ya que estos pertenecen a todas y cada una de las personas, verificándose su vulneración únicamente ante el titular afectado, junto con aceptar el concepto amplio de derecho subjetivo para los derechos sociales, los cuales se encuentran estructurados como derechos individuales, característica fundamental en los derechos subjetivos.

El sujeto pasivo encargado de realizar los deberes derivados de los enunciados normativos que versan sobre los derechos sociales competen al Estado, incluyendo a todos los poderes, y a los particulares en virtud a la eficacia horizontal de los derechos fundamentales realizando acciones negativas y positivas para dar cumplimiento a lo prescrito por las constituciones que contemplan derechos sociales.

El objeto de los derechos sociales corresponde a acciones positivas o prestacionales como también a acciones negativas o de inhibición, característica que se replica en cualquier categoría de derechos, lo que permite sostener que todos los derechos fundamentales se estructuran de manera heterogénea, es decir, como derechos de acción y omisión.

\section{BIBLIOGRAFÍA}

Abramovich, V., y Courtis, C., Los derechos sociales como derechos exigibles, Trotta, Madrid, 2002. Alexy, R., Teoría de los derechos fundamentales, Centro de Estudios Políticos y Constitucionales, Madrid, 1997.

Alexy, R., “Derechos Sociales Fundamentales”, en Carbonell, M., Cruz Parcero, J.A. y Vázquez, R. (Comp.), Derechos sociales y derechos de las minorias [En línea] http://www.bibliojuridica. org/libros/4/1658/4.pdf, 2000.

Ansuátegui Roig, F., “Argumentos para una teoría de los derechos sociales”, en Revista Derecho del Estado, Vol. 24, 2010, pp. 45-64.

AÑon Roig, M.J., "La contribución de los derechos sociales al vínculo social”, en Añon Roig, M.J. (et al.), El vínculo social: ciudadanía y cosmopolitismo, Tirant lo Blanch, Valencia, 2002.

Arango, R., El Concepto de Derechos sociales fundamentales, Legis, Bogotá, 2005.

Atria, F., “¿Existen derechos sociales?”, en Discusiones (Publicaciones periódicas) [En línea] http:// descargas.cervantesvirtual.com/servlet/SirveObras/01826630549036114110035/015570. pdf? incr $=1$ Vol. 4, 2004.

Atria, F., "Réplica: derecho y política a propósito de los derechos sociales", en Discusiones (Publicaciones periódicas) [En línea] http://descargas.cervantesvirtual.com/servlet/ SirveObras/06923896589547328537857/015574.pdf? incr $=1$ Vol. 4, 2004.

Baldesarre, A., Los derechos sociales, Serie de Teoría Jurídica y Filosofía del Derecho, Universidad Externado de Colombia, Bogotá, Colombia. 2001.

Barnes, J., "Introducción al Principio de Proporcionalidad en el Derecho Comparado y Comunitario", en Revista de Administración Pública [En línea] http://www.cepc.es/rap/ Frames.aspx? IDS = sflevg 55 mopfj0ulcxko3dnx_71298\&ART = 1,23969,1994_135_495. PDF, Vol. 135, sept-dic 1994. 
Bernal Pulido, C., "Fundamento, concepto y estructura de los derechos sociales. Una crítica a “¿Existen derechos sociales? de Fernando Atria”, en Discusiones (Publicaciones periódicas) [En línea], http://descargas.cervantesvirtual.com/servlet/SirveObras/12937957558077187421624/015573. pdf? incr $=1$ Vol. 4, 2004.

BöCKENFÖRDE, E.W., Escritos sobre derechos fundamentales. Nomos Verlagsgesellschaft, BadenBaden, 1993.

Bulnes Aldunate, L., "El Derecho a la Protección de la Salud en la Constitución de 1980", en Gaceta Jurídica, Vol. 295, 2005.

Carbonell, M., "Eficacia de la Constitución y Derechos Sociales: esbozo de algunos problemas", en Revista Estudios Constitucionales, Vol. 6, No 2, 2008, pp. 43-71.

Celis Danzinger, G., "Los Derechos Económicos, Sociales y Culturales. Limitaciones y Proyecciones", en Nomos Vol. 2, 2008, pp. 59-90.

Contreras, P. Poder Privado y Derechos. Eficacia horizontal y Ponderación de los Derechos Fundamentales. Ediciones Universidad Alberto Hurtado, 2009.

Contreras Vásquez, P., García Pino, G., Jordán Díaz, T. y Villanueva Rojas, Á., "Informe en Derecho Presentando ante el Tribunal Constitucional en el Proceso de Inconstitucionalidad del Artículo 38 Ter de la Ley Nº 18.933", en Revista Estudios Constitucionales, Vol. $8 \mathrm{~N}^{\circ} 2$, 2010, pp. 633-674.

Cruz Parcero, J.A., "Los Derechos Sociales como técnica de protección jurídica”, en Carbonell, M., Cruz Parcero, J.A. y Vázquez, R. (Comp.), Derechos sociales y derechos de las minorías [En línea] http://www.bibliojuridica.org/libros/4/1658/5.pdf, 2000.

Cruz Parcero, J.A., El lenguaje de los derechos: ensayo para una teoría estructural de los derechos, Trotta, Madrid, 2007.

Ferrajoli, L., "Derechos Fundamentales", en Los Fundamentos de los Derechos Fundamentales, Trotta, Madrid, 2001.

Ferrajoli, L., Derechos y Garantías. La ley del más débil. Cuarta Edición, Trotta, Madrid, 2004.

Figueroa García-Huidobro, R., "Justiciabilidad del Rol de las Cortes Haciendo Justiciables los Derechos Económicos, Sociales y Culturales, en particular, el Derecho a la Protección de la Salud", en Revista Chilena de Derecho, Vol. 36 N² 2, 2009, pp. 313-342.

Figueroa García-Huidobro, R., "Justiciabilidad de los Derechos Económicos, Sociales y Culturales. Discusión Teórica", en Revista Chilena de Derecho, Vol. 36 N³ 3, 2009, pp. 587-620.

Gavara de Cara, J.C., "Los Derechos Fundamentales", en Gavara de Cara, J.C. (Ed.), Desarrollo, Rasgos de Identidad y Valorización en el XXV Aniversario (1978-2003), J. M. Bosch Editor Institut de Ciences Politiques i Sociales, 2004.

Guastini, R., Distinguiendo, Gedisa, Barcelona, 1999.

Jellinek, G., Teoría general del Estado, Fondo de Cultura Económica, Ciudad de México, 2000.

Jordán Díaz, T., La Protección de los Derechos Sociales: Modelos Jurisprudenciales Comparados de tutela en España y Chile, Colección de Investigaciones jurídicas $\mathrm{N}^{\circ} 10$, Facultad de Derecho Universidad Alberto Hurtado, 2006.

Jordán Díaz, T. "Algunos comentarios a la Sentencia del Tribunal Constitucional No 976/2008", en Nomos, Vol. 2, 2008, pp. 263-274.

Jordán Díaz, T., "El principio de contribución constitucional y la abrogación del principio de subsidiariedad en materia de derechos fundamentales sociales", en Ferrada, J.C (Coord.), Estudios de Derecho Público. El principio de separación de poderes, Actas de las XL Jornadas de Derecho Público 2010, Abeledo Perrot - Thompson Reuters, Santiago, 2011.

Kelsen, H., Teoría Pura del Derecho, Cuarta Edición, Cuarta Reimpresión, Eudeba, Buenos Aires, 2005. López Fernández, D. Los Derechos de las Personas: La Fuerza de la Democracia. Ediciones Universidad Alberto Hurtado, 2009. 
Martínez Estay, J.I., "Lección Undécima. Los Derechos Sociales”, en Pereira Menault, A.C., Teoría Constitucional. Segunda Edición chilena. LexisNexis, 2006.

Martínez Estay, J.I., "Los Derechos Sociales: Una reflexión a propósito de la sentencia Rol 976 del Tribunal Constitucional", en Nomos, Vol. 2, 2008, pp. 275-290.

Martínez Estay, J.I., "Los Derechos Sociales de Prestación en la Jurisprudencia Chilena”, en Revista Estudios Constitucionales, Vol. 8 N $^{\circ}$ 2, 2010, pp. 125-166.

Nash Rojas, C., "Los Derechos Económicos, Sociales y Culturales y la Justicia Constitucional Latinoamericana: Tendencias Jurisprudenciales”, en Revista Estudios Constitucionales, Vol. 9 $\mathrm{N}^{\circ} 1,2011$, pp. 65-118.

Pachot, K., "A Propósito del Carácter Fundamental de los Derechos Económicos, Sociales y Culturales. Una Mirada desde la Doctrina Comparada y la Experiencia del Ordenamiento Jurídico Cubano”, en Revista Estudios Constitucionales, Vol. 8 No 1, 2010, pp. 13-42.

Parejo Alfonso, L., "El Contenido Esencial de los Derechos Fundamentales en la Jurisprudencia Constitucional; a propósito de la Sentencia del Tribunal Constitucional de 8 de abril de 1981", en Revista Española de Derecho Constitucional [En línea], http://www.cepc.es/rap/ Publicaciones/Revistas/6/REDC_003_169.pdf, Vol. 3, 1981.

Peces-Barba, G., Curso de derechos fundamentales: teoría general, Universidad Carlos III de Madrid, Boletín Oficial del Estado, Madrid, 1999.

Pisarello, G., Los derechos sociales y sus garantías. Elementos para una reconstrucción, Trotta, Madrid, 2007.

Prieto Sanchís, L., "Los derechos sociales y el principio de igualdad sustancial", en Carbonell, M., Cruz Parcero, J.A. y Vázquez, R. (Comp), Derechos sociales y derechos de las minorías [En línea] http://www.bibliojuridica.org/libros/4/1658/3.pdf, 2000.

Riveros Pardo, D., "Los derechos económicos, sociales y culturales como derechos subjetivos: una visión estructural”, en Revista Derecho del Estado, Vol. 24, 2010, pp. 29-43.

Ross, A., Sobre el derecho y la justicia, Tercera Edición, Primera Reimpresión, Eudeba, Buenos Aires, 2006.

Tugendhat, E., Lecciones sobre ética, Gedisa, Barcelona, 1997. 
